\title{
Franck Cochoy (forthcoming, 2016) On Curiosity: The Art of Market Seduction. Manchester: Mattering Press. 138 pages. ISBN: 978-0-9931449-4-3.
}

\author{
Gay Hawkins \\ g.hawkins@westernsydney.edu.au
}

Striptease, packaging, click bait, shop windows. What do these disparate things have in common? They all work on the assumption that an interested subject wants to know and see more. Or, to put it more simply, they all provoke curiosity. Devices to activate curiosity are everywhere around us, and many of our modes of being in the world are driven by curiosity yet this phenomenon remains strangely unexamined. It is not until you read Franck Cochoy's wonderful book On Curiosity (one of the first published by the exciting new open access Mattering Press) that you realise how little we know about curiosity, and how central it is to so many ordinary practices. From the opening pages Cochoy makes us curious about curiosity. The book has a compelling intellectual energy, you can feel Cochoy's desire to know more about curiosity, to 'unpack' it, and this energy is contagious. An author wanting to know more ... produces a book ... that provokes a reader ... who wants to know more: this is the force of curiosity at work. Cochoy is not ashamed about his curiosity about curiosity, instead he celebrates it as fundamental to the intellectual disposition. And what a refreshing admission this is.

The explicit project of the book is to develop a history and sociology of curiosity through the example of the market. As one of France's leading economic sociologists working in the STS/ANT tradition Cochoy has produced an impressive and influential body of research that has consistently foregrounded the role of devices in organ- ising markets. From packaging to the shopping trolley to data matrixes Cochoy has examined how markets are agenced by sociotechnical artefacts. In this study these and many other devices are re-examined with the aim of understanding exactly how they work as 'captation devices', or tools for equipping relationships between organisations and their users or audiences. Captation devices are not designed to manipulate rather to capture. That is, they ascribe an attitude to people that is familiar or that they are willing to give attention to, and they suggest a possible mode of action that they may not necessarily have had in mind. The key attitude or disposition that Cochoy examines is curiosity: what particular devices activate it and allow it to be expressed throughout society? And what types of actions does it prompt?

Before getting to the issue of markets as the heartland of curiosity, as the site where curiosity finds its 'natural' home and contemporary commercial realisation, Cochoy takes us on a journey through the intellectual history of curiosity. This is not a review of the existing literature. For a start there is surprisingly little but, more significantly, Cochoy is far too creative a thinker to use that worn out analytic device. Rather, it is a rich exploration of the complex cultural work that expressions of curiosity have performed over centuries with the aim of understanding how curiosity becomes so central to the rise of market societies. Using a detailed analysis 
of the tale of Bluebeard, a fairy story about a wife who was unable to resist the lure of curiosity, Cochoy analyses how this story works as a profane version of earlier religious and mythical accounts of the moral dangers of curiosity. With great skill and precision the reader is taken through the various processes whereby curiosity is secularised. While religion and myth framed curiosity as both inherent to the human condition and also dangerous, the enlightenment relocated it within the realms of organised knowledge and the positive desire to know the world. Science legitimated curiosity but also disciplined it, literally and metaphorically. Public experiments, the rise of observation and fieldwork, natural history displays all worked to activate curiosity and also regulate it. In many senses what Cochoy is often describing is the governmentalisation of curiosity, the processes whereby it becomes incorporated into the management of populations and the conduct of conduct, as Foucault terms it. In the rise of the museum, we don't simply see the displacement of cabinets of curiosity with virtuous curiosity driven by the quest for knowledge for its own sake. We also see how looking at a collection expresses a pedagogic imperative; the desire to improve specific populations through the activation of managed curiosity.

The marketization of curiosity is Cochoy's primary focus. Over three chapters a series of devices and arrangements central to the rise of the modern commercial economy are examined. Window displays, packaging, advertising, data matrixes and more are analysed in terms of exactly how they made curiosity benefit markets. These analyses are richly historical and empirical. They also draw on numerous disciplines from sociology, to philosophy to anthropology. It is impossible to do justice to the complexity of these examples except to say that they foreground both the specificity and multiplicity of ways in which curiosity can be activated within markets - as any device centred analysis should. So, for example, in the analysis of the rise of window displays phenomenological accounts of the meanings of doors, locks and mirrors are drawn on to show how curiosity is activated in a looking subject when they encounter the shop window. And how this activation pulls the subject into a world of objects and a distinct form of consumer captation. Other examples examine the relationship between packaging and surprise, the role of advertising billboards in making curiosity a generative public event and the ways in which data matrixes on goods only grant access to the knowledge they possess when they are activated.

What links these cases and gives them coherence is a thoroughly STS commitment to understanding how technologies prompt curiosity, how they make it real. Cochoy is interested in how curiosity is done or performed in market relations and that means refusing to see it as an internal expression of subjectivity. One of the most powerful and convincing lines of thought in this book is the insistence that curiosity is not a human motive or action that is spontaneously available. It has to be aroused or activated and not only is this process distributed across a myriad of market relations but the techniques for arousing it shape its expression. This argument disrupts neat distinctions between market dispositifs and consumer dispositions. Instead, Cochoy argues, the work of qualification works both ways: it qualifies goods and their social spaces and people by offering them motives and actions that justify becoming attached to goods; that realise specific types of consumer curiosity.

There is much more to say about the complexities of curiosity and market seduction set out in this book but let me finish with a few points about its significance for wider debates within STS. I read On Curiosity soon after finishing Muniesa's (2014) The Provoked Economy. Inevitably, both books entered into a conversation. This conversation focussed on the similarities and differences between the terms: 'provoked' and 'activated'. 'Activated' is a term Cochoy uses a lot, along with aroused, cultivate and awakened, it foregrounds the dynamic ways in which markets are animated or realised. In his account curiosity works as a force that is not grounded in either buyers or sellers rather, it is an effect that must be enacted to make markets work. Consumers must identify it as a motive for action and sellers must find the right devices to awaken or call it up. The activation of curiosity is generative of market relations and dispositifs. For Muniesa, 'provocation' refers to a performative take on reality or the ways in 
which the real is realised as an effect of various provocations. Technology or devices or experiments provoke effects, they trigger latent energies of everyday life or events and in doing so reveal a new reality. In Muniesa's performative and pragmatist approach categories like consumers, motives, calculations or supply and demand do not precede markets they are an effect of them. Provocation then, is thoroughly compatible with Cochoy's notion of activation in the sense that both concepts frame the social as effectuation or enactment.

However, what is very valuable about Cochoy's account of curiosity is the way in which it foregrounds the activity of activation. All through this book I kept wondering - is curiosity an emotion, a disposition, a passion or what? Cochoy explores all these options. Finally, I understood that it was a force or form of distributed agency that helps make markets. As Cochoy says in the concluding pages 'In spite of all the religious and moral obstacles that have stood in its way, curiosity therefore truly remains a force of action.' While it might seem like an innate human possession the impetus to know, to break out of habits, to investigate the new or explore change has to be aroused and ordered, and in this activation curiosity is both constituted, acquires agency and prompts actions.
One of the longstanding critiques of STS approaches to markets is their failure to develop a critical edge, to account for power and domination. These claims are part of a long debate that I don't wish to revisit. Rather, I want to point to Cochoy's account of curiosity as offering an exemplary way of understanding market powers in a non reductionist way. If we see power not as a noun or possession but as an activity, as a capacity to shape performances in certain ways, then it is possible to understand the significance of curiosity as a force that activates and animates markets and shapes their effects. Cochoy's achievement in this superb book is to show how the force of curiosity has been historically anchored in markets, helping them realise or constitute a multiplicity of realities not just economic ones. His project is not to judge the effects of curiosity but to understand exactly how this force effects or constitutes market realities. This, to my mind, is far more politically valuable than critique for it points to the contingencies of markets and their constant vulnerability to contestation. And, more significantly, to the activation of curiosities that can make trouble for markets and provoke significant political effects. On Curiosity is a great book - thinking like this reminds us of how powerful 'the market' is for investigating so many aspects of the social.

\section{Reference}

Muniesa F (2014) The Provoked Economy. Routledge: London. 